\title{
Vivências comunitárias na contribuição de políticas de gestão de desastres naturais
}

Este trabalho aborda a perspectiva das comunidades residentes em áreas de risco de desastres, e destaca os valores preconizados e estabelecidos pela população como pilares para orientar políticas de gestão de riscos mais eficaz. São expressos os sentimentos, memórias, histórias, percepções e convivências estabelecidas entre atores sociais e as ameaças impostas pelas chuvas, pelo relevo e pela condição de vulnerabilidade social. Compreender as vivências comunitárias possibilita o contato com as suscetibilidades sociais e o reconhecimento da legitimidade das interações estabelecidas pelos atores sociais com o ambiente. Esses achados podem indicar elementos para minimização dos conflitos e contribuir para uma política de justiça territorial. Como ferramenta de coleta de dados, foi aplicado um questionário à 136 indivíduos residentes nas áreas de movimentos de massa, e 12 entrevistas em profundidade com moradores de áreas de deslizamento e inundação, em um município no sul do Brasil, seguida de análise de conteúdo e estatística. O sentimento de pertencimento ao local, as adaptações e estratégias de mitigação, a importância da rede comunitária, além da crença do Divino e descrença nas estruturas institucionais que atuam no campo dos desastres, reflete parte dos resultados desta pesquisa. A vulnerabilidade social é presente e o distanciamento das comunidades com as estratégias adotadas pelos entes públicos chamam a atenção, demonstrando as falhas das políticas de gestão das áreas que apresentam risco. As medidas de proteção, realocação, controle do uso e ocupação das áreas de riscos naturais poderão atenuar as consequências sobre a vida das famílias se o poder público considerar suas histórias, valores e vivências das comunidades.

\section{Community experiences in the contribution of natural hazards management policies}

\begin{abstract}
This work addresses the perspective of communities living in disaster risk areas, and highlights the values advocated and established by the population as pillars to guide more effective risk management policies. The feelings, memories, stories, perceptions and coexistence established between social actors and the threats imposed by the rains, the relief and the condition of social vulnerability are expressed. Understanding community experiences enables contact with social susceptibilities and recognition of the legitimacy of interactions established by social actors with the environment. These findings can indicate elements to minimize conflicts and contribute to a policy of territorial justice. As a data collection tool, a questionnaire was applied to 136 individuals living in areas of mass movements, and 12 in-depth interviews with residents of landslide and flood areas, in a municipality in southern Brazil, followed by content and statistical analysis. The sense of belonging to the site, adaptations and mitigation strategies, the importance of the community network, and the belief in the Divine and disbelief in the institutional structures operating in the field of disasters reflects part of the results of this survey. Social vulnerability is present and the distancing of communities from the strategies adopted by public entities draws attention, demonstrating the failures of management policies in areas at risk. Measures to protect, relocate, control the use and occupation of natural risk areas may mitigate the consequences on the lives of families if the public authorities consider their histories, values and experiences of the communities.
\end{abstract}

Keywords: Natural hazards; Slum; Perception; Public policies.

Topic: Planejamento, Gestão e Políticas Públicas Ambientais

Reviewed anonymously in the process of blind peer
Received: 03/02/2021

Approved: $27 / 02 / 2021$
Danielle Paula Martins (iD)

Universidade Feevale, Brasil

http://lattes.cnpq.br/3495414655243357

http://orcid.org/0000-0002-3591-9899

daniellepaulamartins@gmail.com

João Alcione Sganderla Figueiredo (10)

Universidade Feevale, Brasil

http://lattes.cnpq.br/5064350849922531

http://orcid.org/0000-0002-3693-9752

sganfigue@feevale.br

\section{Teresinha Guerra (iD)}

Universidade Federal do Rio Grande do Sul, Brasil

http://lattes.cnpq.br/4550197393747167

http://orcid.org/0000-0002-6164-2897

tg@ufrgs.br

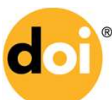

DOI: $10.6008 / C B P C 2179-6858.2021 .002 .0055$

\author{
Daniela Müller de Quevedo \\ Universidade Feevale, Brasil \\ http://lattes.cnpq.br/8409683891631053 \\ http://orcid.org/0000-0003-2169-9781
}

danielamq@feevale.br

\section{Referencing this:}

MARTINS, D. P.; FIGUEIREDO, J. A. S.; GUERRA, T.; QUEVEDO, D. M.. Vivências comunitárias na contribuição de políticas de gestão de desastres naturais. Revista Ibero Americana de Ciências Ambientais, v.12, n.2, p.652-670, 2021. DOI: http://doi.org/10.6008/CBPC2179$\underline{6858.2021 .002 .0055}$ 


\section{INTRODUÇÃO}

Os desastres naturais consistem em um dos principais desafios da atualidade, seja por parte das populações que são atingidas, ou pelas estruturas de gestão que precisam estar preparadas e suportar o número crescente de atingidos, perdas e conflitos associados ao uso e ocupação do solo. No entanto, é válido lembrar que este assunto compõe a discussão internacional há pelo menos 20 anos. Em 2005, foi firmado o Marco da Ação de Hyogo, que previu esforços conjuntos dos países para se prepararem e reduzirem as perdas resultantes dos desastres até 2015. Em 2015, o Marco de Senday destacou a necessidade de construir mecanismo de resiliência visando a prevenção de novos desastres e estabelece quatro prioridades de ação: compreender os riscos de desastres, fortalecer a governança, investir na redução dos riscos e aumentar a preparação (UNISDR, 2015).

Associado ao tema desastres naturais estão as evidências e contexto das mudanças climáticas, que ampliam a perspectiva dos potenciais prejuízos dos eventos naturais em áreas vulneráveis. O CRED ${ }^{1}$ (2015) e UNISDR $^{2}$ (2015) declaram em seus relatórios que, entre os anos de 2005 e 2015, 90\% das principais catástrofes globais foram causadas por inundações, tempestades, ondas de calor, secas e outros eventos relacionados ao clima. Para o UNISDR (2015), "o clima e as mudanças climáticas são os principais impulsionadores do risco de desastres" e Adger (2006) afirma que essas mudanças estão se tornando cada vez mais comuns, e os riscos, e transtornos atrelados às alterações do clima devem nortear a tomada de decisões em todos os níveis.

A América Latina e Caribe apresenta dados que demostram ser uma das regiões mais afetadas por eventos climáticos, especialmente as inundações, as quais se somaram a, cerca de, 41 milhões de pessoas afetadas entre os 2000 e 2019. Essa é a ocorrência mais comum dentre os desastres naturais nesta região do planeta, tendo registrado o maior número de pessoas afetadas na Colômbia e em segundo lugar o Brasil (OCHA, 2020).

Mais recentemente, a World Meteorological Organization (WMO, 2020), em seu relatório - United in Science 2020 Report - destaca que existe a expectativa de o período de 2016 a 2020 ser o mais quente registrado, estando $1,1^{\circ} \mathrm{C}$ superior quando comparado ao período pré-industrial (1850-1900). Myhre et al. (2019) alertam que, a precipitação total com relação à sua frequência, quase duplica por grau de aquecimento global, destacando que as populações humanas podem não estar em condições de suportar adequadamente aos eventos extremos consequentes. A capacidade dos gestores em integrar essas informações são um fator importante para a correta preparação, em especial em casos similares aos da delimitação do trabalho em discussão, que se caracteriza pelos desastres hidrológicos, que são aqueles que se relacionam a precipitação.

Mas muito embora o cenário dos desastres demonstra ser acentuado pelas mudanças climáticas, conforme exposto, salienta-se a importância de trazer para a discussão um aspecto que já é amplamente discutido na ciência: a dimensão do risco, elemento que compõe o cenário de desastres. O risco é tratado

\footnotetext{
${ }^{1}$ Centro para Pesquisa sobre Epidemiologia de Desastres.

${ }^{2}$ Estratégia Internacional das Nações Unidas para a Redução de Desastres - Escritório das Nações Unidas.
} 
sob diferentes perspectivas do conhecimento, mas Beck (1992) e Giddens (1993) apresentam significativas reflexões que podem se aplicar para o tema em questão, que os riscos são produzidos, e que estão relacionados diretamente as escolhas, atividades e decisões humanas. Nesta perspectiva, são distanciadas as questões da crença de se considerar a sorte, as questões divinas ou vontade da natureza, e isso pode ser aplicável na ocorrência dos desastres.

Nesta direção, a teoria social do risco pautará as reflexões desse trabalho, pois estão relacionados diretamente à problemática aqui apresentada que envolvem a comunidade residente nas áreas ameaçadas, que também são atores sociais de mudança local. Com afinco a essa teoria, Natenzon (2016) propõe a desnaturalização dos desastres e dos riscos como estratégia de reconhecimento da influência humana, como fator determinante no cenário dos desastres, e complementa, que é necessário pensar as catástrofes como processos, e não como produtos, partindo para outra forma de análise, além da conjectural que se apresenta.

Ao observar o número de atingidos pelos desastres, que é crescente, e avaliar a forma como muitas cidades do século XXI estão ocupadas, observa-se a ampliação da presença de comunidades em locais que, pelas características de paisagem, são suscetíveis a deslizar ou aquelas que próximas aos corpos d'água, podem inundar. Observa-se que a desigualdade social e o precário planejamento urbano e ambiental são alguns dos fatores responsáveis pela expansão das cidades sobre margens de rios e encostas de morros, áreas naturalmente suscetíveis a desastres. Esse padrão social impulsiona o surgimento de assentamentos irregulares, exclusão territorial e dificuldade de acesso da população carente às oportunidades econômicas e de desenvolvimento humano (ROLNIK, 2006).

Pesquisas apontam que mais da metade das cidades brasileiras são constituídas por assentamentos irregulares, ilegais ou clandestinos, que contrariam, de alguma maneira, as formas legais de urbanização (ROLNIK, 2001). Londe et al. (2014) complementam que os desastres associados a enchentes, movimentos de massa e estiagens provocam danos diversos às populações diretamente vulneráveis a estes processos, além de consequências ambientais, socioeconômicas e sanitárias negativas.

A partir das problemáticas apresentadas, ainda é importante salientar a necessidade de políticas de gestão de riscos eficientes, justas e inclusivas para os locais que estão nesse cenário de riscos de desastres, como já indicaram os marcos da Ação de Hyogo e de Senday (UNISDR, 2015). A gestão de riscos é uma possibilidade de intervenção humana na tentativa de reduzir ou modificar os riscos. Porém, são exemplos recorrentes na América Latina, o manejo das populações mais expostas aos perigos, com realocações para locais que são produzidos sem a menor participação social. E ainda, conforme lembra Valencio (2009), "o deslocamento involuntário dos moradores da área de risco dá-se na desconsideração dos vínculos desses com sua moradia, relações e hábitos especializados", resultando em descontentamento e ineficácia dos programas de habitação, o que repercute no retorno das famílias para os locais de origem, além de degradação das estruturas humanas e sociais daqueles que são alvo destas práticas.

Considerando que as tentativas de compreender as relações entre humanos e seus ambientes consistem parte importante das pesquisas acadêmicas, a exemplo de trabalhos da antropologia como fez Descola em sua imersão em uma população da Amazônia, os Achuar Jivaro, apresentado por Campos (2013) 
ou na mesma linha, Castro (1996). Figueiredo et al. (2014), problematiza a percepção dos riscos a partir da indústria de curtimento e aponta que somente através da integração entre sociedade e ciência será possível construir processos de decisão que culminem em redução dos efeitos da industrialização ao ambiente.

Como o escopo deste trabalho está na compreensão das percepções e vivências de comunidades em áreas com riscos de desastres, é importante salientar os esforços de Kates (1962) que buscou compreender a reação de comunidades de áreas de risco de inundação nos EUA, e O'Connor et al. (1999) com seus levantamentos relacionados à percepção e mudanças climáticas deste país, Chardon (1997) na Colômbia e Puy et al. (1997) na Espanha e Tavares et al. (2011), em Portugal. No Brasil, corroboram nesta abordagem, Souza et al. (2009) com estudos aplicados com comunidades de Minas Gerais e Espírito Santo, Favero et al. (2016), no Rio Grande do Sul e Ardaya et al. (2017) no Rio de Janeiro.

Slovic (2010) reforça a importância de considerar a visão dos atores sociais nos processos de gestão de riscos, quando cita que "But serious attention to participation and process issues may, in the long run, lead to more satisfying and successful ways to manage risk". Aqui assume-se que compreender a perspectiva social daqueles que são atingidos pelos eventos que resultam em desastres auxiliará a melhorar o conhecimento das estratégias sociais que podem ampliar a resiliência, aproximar-se dos valores que são fundamentais e que devem ser considerados nos planos de preparação e regularização do uso do solo, mesmo que isso não seja garantia de que será considerado por responsáveis pelas decisões de gestão.

Amparado nos principais autores da temática, este trabalho visa desvelar valores e vivências comunitárias de grupos residentes em áreas de risco que são preponderantes para o desenvolvimento de políticas de gestão de riscos de desastres mais inclusivas e efetivas em escala municipal.

\section{METODOLOGIA}

\section{Lócus de estudo}

O objetivo aqui percorrido utilizou-se para estudo de caso o município de Novo Hamburgo, estado mais ao sul do Brasil, país que se destaca com expressiva participação populacional, econômica e territorial na América Latina. Novo Hamburgo pertencente à região metropolitana da capital do estado do Rio Grande do Sul, com população atual de pouco mais de 250 mil habitantes, foi colonizada por alemães e rapidamente industrializou-se, tendo o segmento calçadista como principal atividade motora de desenvolvimento. Apesar de concentrar expressiva riqueza resultante do processo de industrialização, não conseguiu dimensionar o crescimento aos limites e fragilidades ambientais que a paisagem apresentava, o que resultou em rápida expansão urbana para áreas de alagamento ou com declives acentuados, com casas construídas sem orientação técnica, principalmente pelos operários e emigrantes que foram trazidos de diferentes localidades para fortalecer a força de trabalho. Mesmo no auge do crescimento econômico, em meados de 1960, os investimentos e estruturas viárias se restringira ao centro, e seus bairros contavam com precariedade estrutural e dificuldades em lidar com as chuvas, com recorrentes inundações e contato direto da população periférica com rios poluídos (SELBACH, 1999), a exemplo do que é observado atualmente. 
Assume-se que as condições habitacionais se transformaram intensamente nas cidades latinoamericanas, principalmente em meados do século XX e início do XXI. Cenários de exclusão, segregação social, concentração de riquezas, surgimento de aglomerados, expansão em áreas de riscos, problemas em diferentes escalas intensificaram-se, e passam a exigir políticas urbanas robustas e corretivas para as desigualdades impostas pelo modo de expansão (SPOSITO et al., 2016). No Brasil, o surgimento do Estatuto das Cidades (BRASIL, Lei 10.257/2001) é uma tentativa de ordenar as funções sociais da cidade, e que dentre tantas previsibilidades de aplicação, está o controle do uso do solo urbano de modo a evitar a exposição das populações aos riscos de desastres.

Em Novo Hamburgo, essas áreas de riscos cresceram expressivamente desde a década de 1950 (SELBACH, 1999). Identificou-se em um primeiro mapeamento de áreas de risco de desastres naturais, realizado pelo Serviço Geológico do Brasil - CPRM (CEPED, 2005), o total de 11 setores com alto ou muito alto risco de movimentos de massa e inundações. Os desastres são compreendidos como prejuízos a uma comunidade, ou sociedade, nas qual as atividades são interrompidas, resultando em mortes e perdas das mais diversas ordens como bens materiais, estruturas sociais, infraestruturas e os recursos dessa sociedade atingida, não são capazes de suportar a esses danos (EIRD/ONU, 2004). Evidencia-se que os setores de risco mapeados se situam nas mesmas áreas descritas por Selbach (1999) que abrigaram os migrantes e os operários atraídos pela expansão industrial da cidade, fruto do crescimento da indústria calçadista.

Cabe destacar também o período da desindustrialização observado na cidade, foi fator preponderante para a manutenção e crescimento das áreas periféricas. Com a migração da indústria calçadista para outros lugares e países, muitos trabalhadores perderam suas rendas, e assim, passam a ter que conviver com um território excludente, ocupar lugares com menor custo de vida. O fluxo migratório provocado pelo êxodo rural também reforçada a concentração urbana característica deste período. Ao observar um período de 10 anos percebe-se esse efeito quando, em 1981 a população que era de 7.583 habitantes, passou para 32.263 em 1991, um crescimento de cerca de 425\% (LATUS, 2010).

\section{Procedimentos metodológicos e técnicas}

Os elementos que compuseram os procedimentos metodológicos da investigação são observação participante; survey; realização de entrevistas com moradores, orientação bibliográfica e teórica dos pressupostos aqui abordados.

A observação participante ativa consiste na participação real do conhecimento na vida da comunidade e o pesquisador assume até certo ponto o papel de membro do grupo com interação entre pesquisador e pesquisado. Algumas características foram fundamentais neste processo, como ouvir e visualizar atentamente as rotinas e vivências, participar de momentos comunitários e estabelecer vínculos e parcerias com representantes da comunidade, como líderes e agentes de saúde da família. É um procedimento advindo da técnica etnográfica, e gerou significativas contribuições para a compreensão dos atores e para melhor clarificação dos resultados obtidos pelos demais procedimentos metodológicos.

Para conhecer a real percepção, valores e percepção coletiva da comunidade, também foi preciso 
realizar uma survey e entrevistas com moradores. Para Gil (2008), esse levantamento é apropriado para estudos descritivos, dada sua utilidade para estudos de opinião e de atitudes. O questionário foi elaborado com 40 questões fechadas, as quais foram divididas em: 7 questões que abordam o grau de satisfação sobre segurança, meio ambiente, esgoto, água, resíduos, drenagem e serviços de saúde, com uso da escala likert; 22 questões fechadas com alternativas de múltipla escolha sobre água, esgoto, problemas ambientais, responsabilidades e conhecimento sobre riscos e ameaças, questões de saúde, espaços de lazer, adesão ao lugar e expectativas; 11 questões de identificação e caracterização do entrevistado. Inicialmente as questões foram elaboradas com base na literatura, e teve como principais referências (CUTTER et al., 2003; PUY et al., 2004; ADGER et al., 2009; ALEXANDER, 2011; TAVARES et al., 2011; BRASIL, 2012; FIGUEIREDO, 2014). Este questionário foi submetido à avaliação de um grupo focal de 5 especialistas que realizaram a apreciação, com sugestões e indicação de alterações, a partir do método Delphi (YOUSUF, 2007). Inicialmente foi realizado um piloto de aplicação do questionário a 9 moradores dos 7 setores mapeados pela CPRM (CEPED, 2005) com riscos de movimentos de massa. Para ter uma homogeneidade quanto ao tamanho da amostra foram aplicados dois questionários pilotos nos setores de risco, S_05 R. da Participação e S_04 Vila Esperança devido ao maior número de residências.

A aplicação efetiva dos questionários foi realizada no período de março e julho de 2018, com indivíduos maiores de 18 anos, em 135 famílias residentes nas áreas com risco de movimentos de massa. A população consiste em 202 residências, a partir da estimativa do CEPED/RS (2005), na qual se buscou, por conglomerado, uma amostragem representativa da população residente, com um intervalo de confiança de 95\% e 5\% de margem de erro. Os conglomerados foram divididos em 7 , por ser este o número de locais mapeados pelo CPRM com o risco de interesse da pesquisa, no município de Novo Hamburgo (quadro 1).

Quadro 1: Setores com população e amostra dos conglomerados da pesquisa.

\begin{tabular}{|l|l|l|}
\hline Setores & População (casas) & Amostra (casas) \\
\hline S_4 & 50 & 32 \\
\hline S_5 & 80 & 38 \\
\hline S_6 & 8 & 8 \\
\hline S_7 & 25 & 17 \\
\hline S_8 & 15 & 15 \\
\hline S_9 & 15 & 15 \\
\hline S_10 & 10 & 10 \\
\hline
\end{tabular}

A análise dos dados da survey foi realizada a partir da tabulação em Excel e do software SPSS e a inferência estatística realizada considerando-se um nível de significância de 5\%. Utilizou-se as 7 questões que abordaram o grau de satisfação para proceder à avaliação estatística da survey (quadro 2). A partir do cálculo da média dos valores de satisfação (de 1 a 5 na escala likert), foi possível criar dois clusters e dividir os respondentes entre aqueles que tiveram médias inferiores a 2,5 (grupo 1) e aqueles com valores de média superior a 2,5 (grupo 2). A partir da formação desses dos dois grupos, as demais questões foram submetidas ao tratamento estatístico, utilizando-se o teste Qui quadrado, para identificar associações entre as questões categóricas do estudo. Desse modo 11 questões apresentaram associação significativa com as 7 questões utilizadas como parâmetro para criação dos clusters (quadro 3). 
Quadro 2: Questões que compreendem o grau de satisfação.

\begin{tabular}{|l|l|}
\hline Q.19 & Qual é o seu grau de satisfação com relação à segurança no bairro? \\
\hline Q.20 & Qual é o seu grau de satisfação com relação ao Meio Ambiente no bairro? \\
\hline Q.21 & Qual é o seu grau de satisfação com relação ao esgoto no bairro? \\
\hline Q.22 & Qual é o seu grau de satisfação com relação à água que você toma? \\
\hline Q.23 & Qual é o seu grau de satisfação com relação ao recolhimento do lixo? \\
\hline Q.24 & Qual é o seu grau de satisfação com relação ao escoamento da água da chuva nas áreas que você transita na comunidade? \\
\hline Q.25 & Qual é o seu grau de satisfação com relação aos serviços de saúde \\
\hline
\end{tabular}

Quadro 3: Questões com associação significativa a partir do Qui quadrado.

\begin{tabular}{|l|l|}
\hline Q.4 & Para onde vai o esgoto do seu bairro? \\
\hline Q.5 & De onde vem a água que chega em sua casa? \\
\hline Q. 8 & $\begin{array}{l}\text { Em decorrência destes problemas (problemas ambientais), você conhece alguém que sofreu algum dano material ou } \\
\text { pessoal? }\end{array}$ \\
\hline Q.13 & Você sabe se existem ambientes de lazer (locais de passeio, diversão) no Bairro? \\
\hline Q.16 & Mudaria para outro Bairro? \\
\hline Q.17 & Você percebe alguma mudança ambiental no local que mora? \\
\hline Q.27 & O que você entende por área de risco no seu bairro? \\
\hline Q.30 & Tem poço em casa? \\
\hline Q.31 & Endereço \\
\hline Q.36 & Escolaridade \\
\hline
\end{tabular}

Para complementar a percepção dos moradores, foram realizadas entrevistas semiestruturadas (MYERS et al., 2007) com 12 moradores residentes em quatro bairros que apresentam riscos de movimentos de massa e inundações do município de Novo Hamburgo. Estabeleceu-se ao menos 3 moradores de cada bairro para a realização da entrevista. A seleção destes moradores ocorreu após a realização da survey, integrando moradores das áreas de inundação e o critério preponderante na seleção dos entrevistados foi tempo de residência mínimo de 20 anos no bairro.

As entrevistas foram realizadas entre fevereiro e julho de 2019, as quais foram gravadas para posterior análise. Todos os entrevistados tiveram sua identidade preservada. Foi utilizada a análise de conteúdo Bardin (2009) que consiste em uma análise profunda de significados. Procedeu-se à audição das gravações, à seleção de palavras-chave, à seleção de fragmentos das falas e à congruência entre teoria, falas e categorização. Esta última etapa foi feita de modo a demonstrar a percepção dos entrevistados a partir dos seguintes eixos: a) Vínculos ao lugar e histórico; b) Ameaças e riscos percebidos; c) Confiança nas instituições; d) Expectativas comunitárias.

\section{RESULTADOS E DISCUSSÃO}

\section{Os indivíduos}

A percepção é um elemento fundamental para a compreensão dos valores de um grupo e pode ser desencadeadora de mudanças. Para Figueiredo (2014), somente a percepção coletiva provoca alterações substanciais da realidade, porém se a percepção for individual, ela é menos efetiva. Sendo assim, é imprescindível contemplar instrumentos de análise social do risco e das relações estabelecidas no território para a compreensão dos valores comunitários. A realização da survey significou um ponto de partida fundamental na busca do conhecimento da percepção coletiva pretendida por este trabalho. As entrevistas detalharam aspectos não observados na aplicação dos questionários, com particular riqueza dos meios encontrados pelos moradores no provimento das suas necessidades e dos valores comunitários coletivos. 
Entre os moradores que foram alvo da survey, residentes em áreas de deslizamento, a amostra é composta por $34,8 \%$ de pessoas do sexo masculino e $65,2 \%$ do sexo feminino. A expressiva presença das pessoas do sexo feminino no local de estudo está relacionada ao fato de muitas mulheres desempenham algumas atividades econômicas no contexto do lar. As casas se tornam pequenas creches improvisadas, onde são acolhidas crianças das famílias locais que não acessam os espaços de educação infantil, públicos; cozinhas e salas transformadas em espaços de trabalhos manuais como acabamento de couro ou etapas da produção de calçado que são terceirizadas por indústrias da região; estabelecimentos comerciais como pequenos mercados, bares, venda de refeições prontas; separação e venda de materiais recicláveis em locais improvisados no entorno das casas. Em geral, essas atividades envolvem não apenas os adultos, mas as crianças das famílias que participam como força de trabalho desde muito cedo e com responsabilidades importantes. Em 60,7\% das residências há a presença de, ao menos, uma criança. Com relação ao número de residentes na casa, 20,0\% declarou haver 2 pessoas; 21,5\% informou 3 pessoas; 20,0\% referiu 4 pessoas; 16,3\% selecionou a opção de 5 pessoas e 11,1\% marcou a opção de 6 pessoas.

No contexto, escolaridade, pessoas com ensino fundamental incompleto são 69,6\% dos respondentes. 17,8\% informou possuir ensino fundamental completo. Apenas 1,5\% possui curso superior completo e 10,4\% se declara analfabeto. Quanto à religião, 47,4\% da amostra é católica, 34,1\% é evangélica e 13,3\% declarou não ter religião. A renda familiar é de até $\mathrm{R} \$ 500,00$ em 8,9\% dos casos; até $\mathrm{R} \$ 1.000,00$ em 31,1\%; até $\mathrm{R} \$ 1.500,00$ em 15,6\% e até $\mathrm{R} \$$ 2.000,00 em 28,1\%. Considerando os dados do IBGE (2011), no município de Novo Hamburgo, 26,5\% da população apresentou rendimentos de até R\$1 $1.200,00$ por mês, sendo que nos bairros em estudo, caracterizados como áreas de vulnerabilidade social, esse valor de rendimento abrange $40 \%$ da amostra.

Quando questionados sobre o motivo da escolha daquele bairro como local de moradia, 38,5\% dos respondentes afirmou ser pela existência de familiares ou amigos próximos. 20,0\% informou o principal motivo como sendo o custo de vida e $12,6 \%$ declarou ser devido à localização ou ao trabalho. Do total de respondentes, 64,4\% declarou que não mudaria para outro bairro, contra 35,6\% que mudaria. Tuan (1980) lembra que a topofilia apresenta diversas formas e que o apego por um lugar ocorre por este ser familiar, "porque é o lar e representa o passado ou, ainda, porque evoca o sentimento de posse ou de criação". O apego e o vínculo ao lugar também são fortemente identificados na análise das entrevistas, como pode ser verificado na sequência.

A questão de número 26 indagou os respondentes sobre o grau de segurança das suas casas em relação aos deslizamentos e inundações. Em 40\% das respostas, os moradores declararam o sentimento de muita segurança. 31,9\% disseram se sentir seguros, mas sabem que pode acontecer algum episódio. 8,1\% categorizaram o grau de segurança como regular, pois seus vizinhos já foram atingidos. 15,6 declararam ter pouca segurança, pois já foram atingidos, e 4,4\% não souberam informar. Valencio et al. (2005) corrobora os dados apresentados quando lembra que, para os residentes, a habitação em risco é o lar, e lar é símbolo de segurança para todos, independentemente do local de moradia, o que pode justificar o alto percentual de pessoas que declararam expressivo sentimento de segurança nas suas residências. 
Das 135 habitações visitadas, 65,2\% dos respondentes informou nunca ter recebido nenhuma orientação sobre áreas de risco no local onde reside. 31,1\% informou ter sido visitado pela defesa civil. Mas mesmo com baixo percentual de pessoas que declararam já ter orientação, e aqui não se buscou saber qual orientação técnica recebida, é comum a existência de inúmeras adaptações e estratégias desenvolvidas pelos moradores em suas casas para se auto protegerem e suportarem aos eventos extremos. Ao observar estas, faz lembrar aqui uma "tentativa de certa comunicação estabelecida pelos moradores com o ambiente", ou com os seres não-humanos como chamou Descola na obra de Campos (2013), embora o ambiente em análise neste estudo ser urbano, mas com elementos naturais como a vegetação das encostas, ou o rio e arroios das áreas inundáveis. Também aqui não se quer comparar a relação de moradores de ambientes urbanos com a população indígena observada por Descola ou outros pesquisadores, mas sim, a aproximação ao conceito está na forma de adaptação que consiste em assumir os elementos de risco natural como parte dos seus contextos e valores sociais.

\title{
As percepções, valores e vivências
}

A survey foi direcionada ao grupo residente nas áreas de movimentos de massa, e serão detalhadas de modo a tecer as percepções coletadas nas entrevistas. As entrevistas realizadas contemplaram as áreas de movimentos de massa e inundações, apresentando como os moradores interpretam os riscos a que estão expostos.

No conjunto dos 135 inquiridos na survey, inicia-se com um dado relevante sobre a adesão e satisfação com o lugar. Ao analisar as médias das questões de satisfação (quadro 2), foi possível perceber que $57,8 \%$ dos respondentes se consideram satisfeitos ou muito satisfeitos com as questões do local de moradia (cluster 1). Os demais, 42,2\% correspondem àqueles menos satisfeitos com as questões locais (cluster 2). Esse dado pode ser mais bem compreendido com os fragmentos de falas de alguns moradores que demostram a situação atual quando comparada ao passado. As melhorias estruturais são reconhecidas: ora, em parte, por gestões municipais; ora pelos esforços comunitários.

\begin{abstract}
Aqui era muito ruim quando a gente chegou, o rio entrava sempre dentro de casa, tinha muita morte, sempre tinha um atirado no chão de noite, era a bala comendo solta. Quem conhecia não queria morar aqui. Não dava para deixar as filhas moça na rua. Agora é mais tranquilo, o beco está tranquilo, os meninos (do tráfico) estão em outros lugares também. Agora está bom, quando as bombas (casa de bombas) funcionam, a água não sobe tanto. Minha filha, eu ganho 600 reais por mês, com a reciclagem, eu não estudei, não posso querer coisa melhor, pelo menos as netas podem estudar, e graças a Deus a gente consegue comer, é simples, mas quando eu cheguei aqui a gente passou fome, com duas filhas pequenas, meu marido tinha morrido, e me disseram que era só chegar aqui que tinha trabalho. Eu não tinha com quem deixar as filhas, trabalho tinha, mas muita gente perdeu os filhos na bandidagem, na droga. A maiorzinha cuidava da pequena, mas eu tinha um medo, eu já tinha perdido meu marido. A escola é boa (MORADORA DE ÁREA DE INUNDAÇÃO, 53 anos).
\end{abstract}

Elementos da infraestrutura, como sistema de drenagem das chuvas e equipamentos urbanos, principalmente a escola, compõe parte da satisfação atual, conforme relatado. Além disso, é reportado pelos moradores, a participação substancial da comunidade na instalação de escolas nos bairros, como símbolo de luta e tentativa de acesso aos direitos disponibilizados em outros locais centrais da cidade: "escola era só em 
Novo Hamburgo (centro da cidade), a gente foi atrás, juntamos assinatura de todo mundo, até trancamos rua, a gurizada precisava de escola no bairro, eles deixavam de ir porque era longe" (MORADOR DE 57 ANOS, ÁREA DE INUNDAÇÃO). Aqui cabe referir a nominação dada pelos moradores para a região mais central do município, e destacam uma certa desvinculação ou um senso de não pertencimento ao contexto do município. Isso pode ser resultante da estranheza pelas características físicas e de infraestrutura, que historicamente sempre foram melhor desenvolvidas nas regiões centrais, ou mesmo, pela distância das áreas periféricas, com dificuldades de acesso.

Figueiredo (2014) aponta que a percepção do risco está relacionada à integração dos indivíduos que ali estão com o seu ambiente, a qual pode variar de acordo com o tempo de residência e com o próprio risco a que estão expostos. Em seu estudo, onde avaliou o risco ambiental e tecnológico relacionado à indústria curtidora no vale do Rio dos Sinos, faz alusão ao estranhamento e às dificuldades dos migrantes quando chegavam ao local de trabalho e tinham que conviver com o forte odor, mas que, com o passar do tempo, se acostumavam e passavam a não sentir mais nada, chegando a negar o risco.

Faz parte da lembrança dos moradores a existência dos curtumes no passado. $O$ desconforto com o forte odor era uma das principais reclamações da época, chegando ao ponto de fazer as pessoas passarem mal. A proximidade das casas com as atividades do setor está na memória de muitos entrevistados, que reportam uma melhora do cenário atual, quando comparado com o passado, pelo ambiente com características de poluição em que viviam. Percebe-se a memória do risco tecnológico quando uma entrevistada lembra de como era conviver ao lado de um curtume, o qual, atualmente, não está mais em atividade. Em seu lugar está sendo construído um residencial para habitação de interesse popular.

Esse histórico é importante, pois auxilia no entendimento de que mesmo com a precariedade na infraestrutura observada atualmente nos 11 setores de risco de desastres, a satisfação com o lugar é observada na maioria dos participantes da survey. Nos quadros 4 e 5 são demonstrados novos elementos para essa análise, com as perspectivas comunitárias sobre aspectos estruturais do saneamento básico.

Compondo o universo daqueles que se consideram mais satisfeitos com as condições do ambiente, estão $61,5 \%$ daqueles que tem o esgoto destinado na rede pública e $57,7 \%$ daqueles que têm poços (individuais e compartilhados). Chama a atenção a insatisfação com relação à presença de esgoto a céu aberto $(38,6 \%)$, o que indica as dificuldades em conviver com a problemática do saneamento deficitário. Destaca-se que a Lei 11.445 , de 2007, considera a necessidade de coletar e tratar o esgoto em todo o país. Para isso, estabelece que todos os municípios devem ter um Plano de Saneamento Básico que determine as estratégias para ampliar o tratamento de esgoto.

Quadro 4: Associação da satisfação com a questão sobre destino do esgoto do bairro.

\begin{tabular}{|l|l|l|}
\hline Q.4 Destinação do esgoto do bairro* & Cluster 1 (mais satisfeitos) & Cluster 2 (menos satisfeitos) \\
\hline Rede pública/canalização & $61,5 \%(48)$ & $42,1 \%(24)$ \\
\hline Sumidouro & $6,4 \%(5)$ & $5,3 \%(3)$ \\
\hline Céu aberto & $15,4 \%(12)$ & $38,6 \%(22)$ \\
\hline Não sabe & $14,1 \%(11)$ & $14,0 \%(8)$ \\
\hline Arroio & $2,6 \%(2)$ & $0,0 \%(0)$ \\
\hline Total & $100,0 \%$ & $100,0 \%$ \\
\hline
\end{tabular}

*Associação significativa $(\chi 2=10,912 ; p=0,028)$. 
Quadro 5: Associação da satisfação com a questão da procedência da água de consumo na residência.

\begin{tabular}{|l|l|l|}
\hline Q. 5 Procedência da água de consumo na residência* & $\begin{array}{l}\text { Cluster } \mathbf{1} \\
\text { (mais satisfeitos) }\end{array}$ & $\begin{array}{l}\text { Cluster } \mathbf{2} \\
\text { (menos satisfeitos) }\end{array}$ \\
\hline Poços individuais & $41,0 \%(32)$ & $28,1 \%(16)$ \\
\hline Poços compartilhados & $16,7 \%(13)$ & $8,8 \%(5)$ \\
\hline Da COMUSA - concessionária & $26,9 \%(21)$ & $50,9 \%(29)$ \\
\hline De bicas & $3,8 \%(3)$ & $1,8 \%(1)$ \\
\hline Não sabe & $0,0 \%$ & $3,5 \%(2)$ \\
\hline Da COMUSA - concessionária e bica & $0,0 \%$ & $3,5 \%(2)$ \\
\hline Da COMUSA - concessionária e poços & $11,5 \%(9)$ & $3,5 \%(2)$ \\
\hline Total & $100,0 \%$ & $100,0 \%$ \\
\hline
\end{tabular}

*Associação significativa $(\chi 2=16,762 ; p=0,010)$.

Ainda sobre a preferência da água de consumo ser maior entre aqueles que possuem poços, na questão que abarca a relação entre satisfação e presença de poço na residência (Q.30), a associação significativa $(\chi 2=16,205 ; p=0,000)$ evidencia que $73,1 \%$ dos mais satisfeitos possuem poço nas suas casas, sendo 59,6\% daqueles menos satisfeitos com o local de moradia não possuírem poço na habitação. Esse dado é reforçado por uma das moradoras em sobre a indisponibilidade de água pela empresa concessionária municipal. A comunidade se organiza para obter água subterrânea.

Água aqui só tem dos poços, não chega água da comusa aqui, a gente adora essa água, porque a gente se criou na colônia, e lá era água natural, né. Aqui em cima é mais família, não tem problema, às vezes o caminhão do lixo estoura um saco de lixo, mas não tem problema, só se ali pra baixo (MORADOR DE ÁREA DE DESLIZAMENTO, 57 anos).

A água também compõe parte das estruturas comunitárias existentes, principalmente nas áreas de deslizamento. É comum a presença de "bicas", que são perfurações realizadas pelos próprios moradores, para acessar a água subterrânea, elas são encontradas entre as ruelas e calçadas e suprem a demanda daqueles que não dispõe de água quando chegam na comunidade, até conseguirem construir suas habitações permanentes podem contar com esse recurso.

De forma cotidiana, são observadas diversas transformações nas estruturas da comunidade. Ao percorrer as ruas, que em muitos trechos são de terra, ou pequenos acessos abertos para os transeuntes, desvelam-se inúmeras adaptações executadas pelos moradores, pequenas pontes de madeira sobre os arroios, canais para facilitar a drenagem das águas, aterros com resíduos da construção civil em áreas mais úmidas e obras de canalização com doações massivamente observadas em períodos eleitorais. A moradora de 31 anos complementa este último aspecto: "eu consegui os canos com o vizinho que foi candidato, foi rapidinho, no final de semana já escondemos o esgoto daqui da frente".

O protagonismo dos moradores é observado a partir das obras e estruturas que são implantadas pela própria comunidade, principalmente nos finais de semana. Essa prática é presente desde a construção das primeiras casas de um dos bairros em estudo, em 1984, por meio do projeto João de Barro, que se consolidou como uma grande obra de administração comunitária. Cerca de 400 famílias construíram o seu próprio lar, em sistema de mutirão (LATUS, 2010; REGERT, 2010).

Segundo Leeds (2015), a favela ou os aglomerados urbanos pobres, apresentam alta capacidade de transformação, com concentração de soluções e não somente de problemas, capacidade empreendedora e força de trabalho. As constatações do autor, contrariam o mito de que nestes locais exista apenas a predominância da desordem, da marginalização e de um meio de vida rural, defendido por outros autores. 
A apropriação histórica do lugar, resultante do envolvimento da comunidade no processo de construção das estruturas, como casas, comércio e demandas comunitárias, a exemplo das escolas, pode explicar parte deste sentimento de autonomia e segurança nas soluções coletivas, que ficou evidenciado, a partir do contato com a comunidade. Muitos moradores das áreas de risco residem no local por duas, três ou quatro décadas. Além de constituírem suas famílias, auxiliaram no processo de construção do próprio bairro.

Tem toda a família aqui, primeiro veio à minha mãe e a minha tia, elas compraram as meias, e depois casaram e a família cresceu toda aqui, tem os parentes aqui por perto. Escolhi morar aqui porque não tinha outra opção. Meus pais nasceram na colônia, né, então, quanto menos povoado era, melhor, né. Nós que fizemos a estrada aqui. Não mudaria para outro local. Quando viemos para cá não tinha rua, não tinha nada, era puro mato, quando viemos embora para cá era tudo matão. Nós temos escritura, paguemos imposto, tudo direitinho (MORADOR DE ÁREA DE DESLIZAMENTO, 34 anos).

De acordo com relatos, era comum as pessoas chegarem do interior em caminhões, disponibilizados pelos próprios donos das fábricas, que ofereciam trabalho e transporte de municípios do noroeste e nordeste do Estado. Muitas famílias que chegavam, possuíam vínculo familiar com os trabalhadores que já estavam no Vale dos Sinos, e que eram contatados por telefone ou carta, com oportunidades informadas pelos familiares. "Todos ajudaram a construir as casas, era mutirão no final de semana, e ninguém sabia qual seria a sua casa, então todos faziam as casas iguais. Eu amo aqui, meus filhos cresceram aqui, eu conheço todo mundo" (MORADOR DE ÁREA DE DESLIZAMENTO, 74 anos).

O sentimento de pertença e senso de comunidade construído conforme relato, a partir dos diferentes argumentos destacadas até aqui, embasam os resultados encontrados sobre à possibilidade ou não de mudança para outro bairro, questionada em Q.16 (quadro 3). A partir dos mais satisfeitos, 75,6\% não mudariam de lugar, enquanto entre os menos satisfeitos o percentual é de $49,1 \%$. Os menos satisfeitos estão proporcionalmente divididos em relação à permanência no bairro (associação significativa $(\chi 2=10,107$; $\mathrm{p}=0,001)$ ). Porém, mesmo com forte adesão ao lugar, o quadro 6 corrobora com um novo elemento do território, as precárias opções de lazer disponíveis para a comunidade que também fora reportado por Figueiredo et al. (2017). Percebe-se que a estrutura é limitada ou inexistente, onde mesmo dentre os mais satisfeitos com o local, a maioria salienta a não existência desses espaços, ou os conflitos no uso de espaços como as praças, conforme trechos: "Tem a pracinha ali do escolão, mas sempre tem os maconheiros lá, não dá para ir" (MORADOR DE ÁREA DE DESLIZAMENTO, 51 anos). "Aqui o lazer é na rua, mas se não fosse a escola para eles brinca, não tem onde ir. A gurizada mais velha vai nas padarias, nas lanchonetes, e a igreja que faz os brechós, a gente toma chimarrão e conversa com os vizinhos" (MORADORA DE ÁREA DE INUNDAÇÃO, 38 anos). "Tem a cachoeira, lá no verão, quando chove, a gurizada vai, mas tem que ser corajoso, um já morreu lá" (MORADORA DE ÁREA DE DESLIZAMENTO, 34 anos).

A cachoeira relatada na última fala corresponde a uma antiga pedreira da região. Em atividade de campo conduzida pelos moradores, foi possível conhecer o local e verificar que não existe uma cachoeira, mas os sulcos resultantes da atividade de mineração onde em períodos de chuva geram acúmulos de água que se torna opção de lazer. Este ponto evidencia a relação de apropriação e interação dos moradores com 
a APA existente, com perfeita adaptação das necessidades aos elementos disponíveis, quase como uma relação destacada por Descola na obra de Campos (2013), de incorporação dos elementos locais como parte dos valores sociais.

Pela existência de parte das habitações serem em áreas de proteção ambiental, conforme o Plano Diretor (NOVO HAMBURGO, 2004), Figueiredo et al. (2017) indicou alternativas para recuperação, lazer e turismo na área, com revalorização dos elementos naturais, atividade de baixo impacto nos setores com risco e alternativa para o lazer comunitário. No entanto, as áreas de proteção ambiental, conforme o Plano Diretor, concentram diversidade biológica e ambientes que apresentam limitações no uso, podendo resultar em áreas de risco para a população vulnerável. Neste sentido buscou-se, no quadro 7, o reconhecimento da compreensão de área de risco com os inquiridos pela survey. Merece atenção o significativo percentual dos que apontam como sinônimo de área de risco, aquelas que podem deslizar ou inundar, principalmente dentre o grupo que se classificam como menos satisfeitos. Mas também, ao observar o grupo dos mais satisfeitos, 42,3\% pouco ou nenhuma compreensão informa ter sobre essas áreas. Implica lembrar que, Novo Hamburgo apresentou inúmeros casos de ameaças de desastres, principalmente na última década. Muitas áreas constituem espaços que já tiveram remoção e realocação de famílias, sendo muitas beneficiárias de um auxílio financeiro da prefeitura para aluguel, em detrimento da necessidade de abandono das casas de origem.

Ainda, quando questionados sobre conhecimento da morte de alguém em decorrência dos desastres na vizinhança, há uma associação significativa $(\chi 2=4,444 ; p=0,035)$. Percebe-se que os mais satisfeitos com o local $(76,6 \%)$ não têm conhecimento de alguma perda, contra 59,6\% dos menos satisfeitos.

Quadro 6: Associação da satisfação com o conhecimento sobre a existência de ambientes de lazer no bairro.

\begin{tabular}{|l|l|l|}
\hline Você sabe se existem ambientes de lazer no Bairro? * & $\begin{array}{l}\text { Cluster } \mathbf{1} \\
\text { (mais satisfeitos) }\end{array}$ & $\begin{array}{l}\text { Cluster } \mathbf{2} \\
\text { (menos satisfeitos) }\end{array}$ \\
\hline 1. Não existem espaços de lazer & $37,2 \%(29)$ & $19,3 \%(11)$ \\
\hline 2. Campo de futebol & $5,1 \%(4)$ & $1,8 \%(1)$ \\
\hline 3. Quadra de esportes & $3,8 \%(3)$ & $0,0 \%(0)$ \\
\hline 4. Espaço de eventos & $1,3 \%(1)$ & $0,0 \%(0)$ \\
\hline 5. Praças & $33,3 \%(26)$ & $56,1 \%(32)$ \\
\hline 6. Não sabe & $12,8 \%(10)$ & $22,8 \%(13)$ \\
\hline 7. Quadras e praças & $6,4 \%(5)$ & $0,0 \%(0)$ \\
\hline Total & $100,0 \%$ & $100,0 \%$ \\
\hline
\end{tabular}

*Associação significativa ( $(2=17,058 ; p=0,009)$.

Quadro 7: Associação da satisfação com a compreensão sobre área de risco.

\begin{tabular}{|l|l|l|}
\hline O que você entende por área de risco no seu bairro? * & $\begin{array}{l}\text { Cluster } \mathbf{1} \\
\text { (mais satisfeitos) }\end{array}$ & $\begin{array}{l}\text { Cluster } \mathbf{2} \\
\text { (menos satisfeitos) }\end{array}$ \\
\hline 1. Já ouviu falar, mas não sabe definir & $20,5 \%(16)$ & $14,0 \%(8)$ \\
\hline 2. Área que pode deslizar, inundar & $33,3 \%(26)$ & $57,9 \%(33)$ \\
\hline 3. Local que tem algum tipo de contaminação & $0,0 \%$ & $3,5 \%(2)$ \\
\hline 4. Área que deve ser isolada, não pode ter pessoas, pois tem risco à vida & $9,0 \%(7)$ & $10,5 \%(6)$ \\
\hline 5. Lugar que possui muitas árvores & $7,7 \%(6)$ & $1,8 \%(1)$ \\
\hline 6. Área de encosta, morros e com arroios ou rios & $7,7 \%(6)$ & $7,0 \%(4)$ \\
\hline 7. Nunca ouviu falar & $21,8 \%(17)$ & $5,3 \%(3)$ \\
\hline Total & $100,0 \%$ & $100,0 \%$ \\
\hline
\end{tabular}

*Associação significativa: $(\chi 2=16,478 ; p=0,011)$.

De acordo com Mendes (2015), as representações dadas pelas pessoas sobre o risco "permitem-lhes construir uma sensação relativa de segurança, atribuindo a vulnerabilidade ao outro". As falas a seguir 
marcam o aspecto do reconhecimento do risco e uma tentativa de autossuficiência das famílias em administrar as ameaças: "Aqui em casa não tem perigo, perigoso é ali nas casas bem no alto do moro, aqui graças a Deus, nós fizemos a casa, nunca aconteceu nada, aqui é bem seguro" (MORADOR DE ÁREA DE DESLIZAMENTO, 51 anos). “Aqui eu criei os filhos, morei mais de 30 anos, nunca aconteceu nada. A casa é segura, não tem risco, só tem uma árvore que tinha que tira, que ela está muito alta" (MORADORA DE ÁREA DE DESLIZAMENTO, 72 anos). "Mas sabe que aquelas crianças que morreram era porque a casa tinha uma parede muito fina, a casa estava ruim" (MORADOR DE ÁREA DE DESLIZAMENTO, 64 anos). "A chuva é uma coisa que é de Deus, né, não tem o que fazer. Aqui a gente que se faz tudo, a gente construiu a casa da gente, arruma o que precisa" (MORADORA DE ÁREA DE DESLIZAMENTO, 57 anos).

As narrativas demostram o sentimento citado pelos autores, corroborados por Joffe (1999), indicando que aqueles que ali estão, sinalizam para uma postura que a autora chama do fator "eu não". O envolvimento daqueles que participaram do processo de construção de suas residências se traduz em credibilidade e segurança para com suas habitações. Esse comportamento também é identificado quando são relatadas as estratégias de adaptação e de suporte aos desastres, construídas pelas famílias para conviver com os riscos do local:

Eu fiz esses "murinhos" nas portas, porque a gente acordou um dia e quando colocamos os pés no chão, estava cheio de água, e perdemos tudo, que tristeza, só para ver a sujeira e vê tudo que a gente comprou com dificuldade ir para o lixo. A rua fica que é um rio, mas pelo menos nessas últimas chuvas não entrou mais (MORADOR DE ÁREA DE INUNDAÇÃO, 58 anos).

Eu limpo o arroio, porque quando chove muito a água sobe rápido, e com todo esse lixo que tem aí, pode entrar na minha casa. As pessoas não cuidam, era só todo mundo cuidar nas suas casas, o arroio transborda e tem muito esgoto aí dentro, só para ver o tamanho dos ratos que sai dali (MORADOR DE ÁREA DE DESLIZAMENTO, 40 anos).

Dado o histórico industrial do município, inúmeras famílias chegaram nos anos de 1960, 1970 e 1980 e instalaram-se, construindo ou melhorando estruturas habitacionais mínimas. Além do senso comunitário como força motriz para o desenvolvimento inicial dos bairros, surge a crença às divindades e à figura de Deus como elemento de proteção e de segurança dos moradores nas situações de desastres.

Quando eu era pequena, lá em Cruz Alta, a minha mãe jogava sal no telhado, era para afastar os raios. A gente cuida da casa aqui, né, mas sempre rezando porque já caiu a casa da vizinha, a gente sabe que já teve criança que morreu, mas aqui a casa é segura, mas se Deus não quer, não vai acontecer nada, ele que manda na natureza (MORADORA DE ÁREA DE DESLIZAMENTO, 71 anos).

Eu tenho medo, né, minha filha, mas a gente não tem outra opção. É aqui que a gente sabe morar, onde a gente criou os filhos e onde os filhos moram, tem tudo aqui, todo mundo se ajuda. Quando a gente chegou aqui as pessoas ajudavam mais, mas a gente conhece todo mundo, sabe com quem pode se meter e quem a gente tem que obedecer. $E$ não tem lugar seguro, né, então a gente sempre lembra que está na companhia de Deus, que a gente não está sozinho (MORADOR DE ÁREA DE INUNDAÇÃO, 67 anos).

Quando nós ganhamos a casinha lá no Boa Saúde (bairro em que muitos moradores de áreas de risco foram realocados), eu só rezava, se não fosse por Deus eu não sei o que tinha acontecido. Não tinha nada lá, não conhecia ninguém, a Doutora disse que eu fiquei com Depressão, ela me deu remédio e tudo. Mas graças a Deus a gente voltou para cá, eu só pedia para Jesus Cristo nosso senhor, me dá minha casinha de volta. Aí a gente conseguiu juntar um dinheirinho e compramos aqui de novo (MORADORA DE ÁREA DE INUNDAÇÃO, 72 anos). 
Em diversos momentos, os moradores reportam a crença em divindades como simbolismo de segurança e proteção. Além da crença, existe um conformismo com relação à ocorrência dos desastres, sendo, repetidas vezes, justificados como vontade divina. Lopes (2018) enfatiza, em sua investigação, que a religiosidade se apresenta como explicação para os episódios de desastres, demonstrando-os como acontecimentos únicos, além de evidenciar aqueles que sobrevivem como sendo merecedores da dádiva divina ou escolhidos por Deus para resistir.

As falas também demonstram que as forças da natureza, muitas vezes, aparecem como manifestações sagradas, concluindo que os fenômenos naturais são decisões de Deus, excluindo a participação e a influência humana. Pádua (2010) corrobora a tese de que a aceitabilidade da relação entre atividades dos humanos e as alterações ao ambiente natural ficaram evidenciadas muito recentemente: somente a partir de 1970 essa teoria passa a se confirmar de modo amplo. Quando se busca a compreensão do modo como se articulam as estratégias de segurança dentro da comunidade, surgem falas que demonstram pouca confiança no Estado e a descrença no saber técnico.

Depois do deslizamento que teve, que morreu as crianças, eu pedi para o cara da prefeitura olhar minha casa, ele disse que não tinha nada, era seguro... um dia eu estava trabalhando e me ligaram para voltar para casa correndo, que minha casa tinha deslizado. Se não fosse o meu maior (filho), que tinha feito curso de bombeiro, que percebeu o que estava acontecendo, os três tinham morrido... ele salvou os irmãos e a vizinha. E eu fui atrás, eu fiquei preocupada depois do que aconteceu, mas não dá para confiar na prefeitura (MORADORA DE ÁREA DE DESLIZAMENTO, 41 anos).

Eles já vieram aqui, falaram que é uma área de risco, mas eu não acredito, então tem que tirar todo mundo, quanta gente vive em lugares assim, a gente vive aqui a um punhado de anos, nunca aconteceu nada, eles querem mandar a gente lá para o Boa Saúde, mas até lá que deslizou agora, então onde é seguro? (MORADOR DE ÁREA DE DESLIZAMENTO, 67 anos).

Além da relação entre moradores e Estado, que pouco ou nada articula o fazer técnico ao fazer comunitário, marcada por imposições e tentativas de higienizar a cidade, com remoções arbitrárias, como faz lembrar Valencio (2009), parte da descrença no conhecimento técnico também pode ter como componente o grau de escolaridade dos moradores. 91\% dos mais satisfeitos são analfabetos ou não concluíram o ensino fundamental. No grupo dos menos satisfeitos identifica-se a presença de um número maior de pessoas com ensino fundamental completo $(31,6 \%),(\chi 2=15,881 ; p=0,003)$. A escolaridade, conforme defendido por Almeida (2010), é um dos fatores que contribuem para o aumento da vulnerabilidade social, principalmente quando os índices de escolarização da população apresentarem valores baixos.

Os entrevistados ainda reportaram que são frequentes os episódios de inundação. Sabem que são poucas as opções de realocação das famílias em situação de risco. Também demonstram as estratégias adotadas para suportar as inundações, como a construção de um segundo piso nas casas ou o acolhimento de bens de vizinhos até as águas baixarem. É comum, principalmente após tempestades, a distribuição de lonas por parte da defesa civil. Os moradores salientam que não é possível esperar até chegar o auxílio, sendo que alguns já perderam tudo como cita um morador de área de inundação, de 53 anos "Aqui não entrava água, depois que fizeram as obras da Palmeira é que começou a ter inundação". 
No âmbito das expectativas comunitárias, os dados demonstram certa descrença na mudança e isso pode ser fruto de políticas de gestão top dow, em que as decisões são tomadas pelos representantes políticos, sem considerar as necessidades e construções da comunidade, resultando em modelos que não geram inclusão social, que menosprezam interesses e demandas sociais. As adaptações e modificações realizadas pela comunidade nas áreas de risco, demonstram uma certa resiliência social aos desastres, do mesmo modo que expressam os atores locais como agentes de produção do espaço, repleto de protagonismo. Mesmo ancorado em valores e crenças religiosas sobre a ocorrência do desastre, reagem e estabelecem comunicação com o local de habitabilidade, conforme lembrou Descola.

Guivant (1998) considera a presença da banalização dos conhecimentos peritos, polarizando as duas formas respectivas de saber. Por outro lado, Valencio et al. (2009) expõe que, muitas vezes, a população que reside em áreas de risco não comunica aos órgãos de gestão de riscos, como a defesa civil, por receio de sofrer processos de remoção e perda das habitações. Em consonância a isso, não se pode deixar de citar as relações de poder e gestão que surgem localmente nas áreas de estudo. Leeds (2015), lembra que é característico em favelas e áreas pobres a incidência de organizações que controlam os recursos comunitários, toma decisões, exercem domínio político e regulam aspectos habitacionais, como a cobrança de aluguéis, a expansão das áreas e até a força de trabalho e por vezes, isso ocorre com ou sem a participação do estado. A exemplo disso, o trecho a seguir ilustra as características desse poder sobre a comunidade:

Aqui onde eu moro tem um dono, está certo! Eu pago 400 reais todo mês para morar aqui, eu não posso reclamar porque se não fosse por ele eu estava morando na rua sabe, é simples, mas não me falta nada, até comida quando eu me aperto ele me ajuda, e ajuda muita gente e ninguém mexe com a gente. Só que meu filho mais novo trabalha para ele, só Deus sabe o quanto eu sofro, eu tomo tanto remédio, não tenho como trabalhar, esse meu filho aparece de vez em quando. Tem gente aqui que vende terra, é só você escolher, eles mandam vir o mato abaixo e aí é só erguer o barraco, ninguém mora aqui de graça. (MORADORA DE ÁREA DE DESLIZAMENTO, 67 anos).

Ao analisar as lideranças e atuação comunitária, observou-se representantes locais, que em alguns casos, replicam os modelos políticos predominantes, com foco nas ambições individuais e em cargos políticos. O senso de autonomia e resolução de comunidades periféricas ficou evidente, o que se alinha a visão de Leeds (2015) ao apresentar um novo olhar para as favelas e comunidades carentes. Destaca o protagonismo e poder de decisão, longe do que margeava parte das discussões acadêmicas que demonstravam características de vitimização e fragilidade.

Sobre o risco de desastres, surge como uma consequência do ambiente no qual outros benefícios do local se sobrepujam a este, fatores como as relações sociais, características da paisagem e falta de opção/recursos financeiros são preliminares à decisão por estar ou não no local. Dentre as mulheres da comunidade, além da existência de redes de apoio no cuidado com os filhos, demonstrar ser um valor fundamental na permanência nos locais, a proteção propiciada por aqueles que exercem o poder sobre o local assegura o atendimento de necessidades básicas, muitas vezes não ofertadas pelo poder público ou em outros lugares.

Por fim, não se pode deixar de lembrar de Beck (1992) e Gidens (1993), que trazem a reflexão que os riscos estão ligados as decisões humanas. É premente que as decisões sobre o território sejam orientadas em 
garantir os direitos humanos, considerando os aspectos do passado como preditores de parte das mazelas sociais, na construção de um novo modo de desenvolvimento que mais inclua do que tipifique as populações.

\section{CONCLUSÕES}

Através desse estudo foi possível identificar as relações territoriais estabelecidas nas áreas de risco de desastre, que com as suas características sociais, físicas e especificidades culturais, abarca um arcabouço social útil para pensar os conflitos urbanos no contexto do risco de desastres. São elementos um tanto invisíveis, que exigem sensibilidade técnica, e ainda pouco explorados na consideração de políticas de gestão de risco de desastres, porém, que são valores fundamentais para as populações que vivem e produzem as cidades.

As comunidades estudadas são caracterizadas como espaços de risco natural, o que tecnicamente é possível demonstrar com a cartografia tradicional. Porém, os estudos de percepção e de escuta social, como a presente investigação, apontam que a simples análise de um local a partir dos elementos físicos ou das categorizações legais, não são satisfatórios para a resolução dos conflitos territoriais.

A proposta de reflexão deste artigo evidencia a necessidade de uma discussão que supere a necessidade de apontar exclusivamente os moradores como culpados ou a simples falta de gestão pelos órgãos. Se corrobora que a situação atual é um ponto que deve ser objeto de ampla discussão, com a consideração demográfica dos valores aqui descritos, devendo ser superado o modelo tecnicista e excludente que considera exclusivamente os limites da formalidade da cidade.

\section{REFERÊNCIAS}

ADGER, W. N.. Vulnerability. Global Environmental Change, v.16, n.3, p.268-281, 2006. DOI:

https://doi.org/10.1016/j.gloenvcha.2006.02.006

ADGER, W. N.; DESSAI, S.; GOULDEN, M.; HULME, M.; LORENZONI, I.; NELSON, D. R.; NAESS, L. O.; WOLF, J.; WREFORD, A.. Are there social limits to adaptation to climate change?. Climatic Change, v.93, n.3, p.335-354 2009. DOI: https://doi.org/10.1007/s10584-008-9520-z

ALEXANDER, D.. Modelos de vulnerabilidade social a desastres. Revista Crítica de Ciências Sociais, v.93, n.1, p.929, 2011.

ALMEIDA, L. Q.. Vulnerabilidade socioambiental de Rios urbanos: bacia hidrográfica do Rio Maranguapinho região metropolitana de Fortaleza-Ceará. Tese (Doutorado em Geografia) - Universidade Estadual Paulista "Júlio de Mesquita Filho", Rio Claro, 2010.

ARDAYA, A. B.; EVERS, M.; RIBBE, L.. What influences disaster risk perception? Intervention measures, flood and landslide risk perception of the population living in flood risk areas in Rio de Janeiro state, Brazil. International Journal of Disaster Risk Reduction, v.25, p.227-237, 2017. DOI: https://doi.org/10.1016/j.ijdrr.2017.09.006

BARDIN, L.. Análise de Conteúdo. 7 ed. Portugal: Geográfica, 2009.
BECK, U.. La sociedad del riesgo. Hacia una nueva modernidad. Barcelona: PAIDOS, 1992.

BRASIL. Lei n. 10.257, de 10 de julho de 2001. Estatuto da Cidade. Regulamenta os arts. 182 e 183 da Constituição Federal, estabelece diretrizes gerais da política urbana e dá outras providências. Brasília: DOU, 2001.

BRASIL. Lei Federal n. 12.608, de 10 de abril de 2012. Institui a Política Nacional de Proteção e Defesa Civil - PNPDEC e dá outras providências. Brasília: DOU, 2012.

CAMPOS, R.; DAHER, A.. A antropologia da natureza de Philippe Descola. Topoi, Rio de Janeiro, v.14, n.27, p.495517, 2013. DOI: https://doi.org/10.1590/2237$\underline{101 \times 014027013}$

CASTRO, E. V.. Os pronomes cosmológicos e o perspectivismo ameríndio. Mana, Rio de Janeiro, v.2, n.2, p.115-144, 1996. DOI: https://doi.org/10.1590/S0104$\underline{93131996000200005}$

CEPED/RS. Centro Universitário de Estudos e Pesquisas sobre Desastres do RS. Projeto Mapeamento de Vulnerabilidades a Áreas Suscetíveis à Inundações e Deslizamentos em $\mathbf{8}$ municípios do RS. CEPED, 2005. 
CHARDON, A. C.. La percepción del riesgo y los factores socioculturales de vulnerabilidad: caso de ciudad de Manizales, Colômbia. Revista Desastres y Sociedad, n.8, p.434, 1997.

CRED. Centre For Research on The Epidemiology of Disasters; The un Office for Disaster Risk Reduction. The Human Cost of Weather-Related Disasters 1995-2015. Belgium, 2015. DOI:

http://doi.org/10.13140/RG.2.2.17677.33769

CUTTER, S. L.; BORUFF, B. J.; SHIRLEY, W. L.. Social Vulnerability to Environmental Hazards. Social Science Quarterly, v.84, n.2, p.243-261, 2003. DOI: https://doi.org/10.1111/1540-6237.8402002

EIRD/ONU. Estratégia Internacional de Redução De Desastres. Vivir com el riesgo: informe mundial sobre iniciativas para La reducción de desastres. Nova lorque: Secretaria Interinstitucinal de La EIRD, 2004.

FAVERO, E.; TRINDADE, M. C.; PASSUELLO, A.; PAULETTI, C.; FORESTI, A. J.; CASTELLÁ SARRIERA, J.; SILVA FILHO, L. C. P. Percepção de risco ambiental: uma análise a partir de anotações de campo. Revista Interamericana de Psicologia, v.50, n.1, p.64-74, 2016

FIGUEIREDO, J. A. S.; LENZ, C. A.; NUNES, M. F..

Aproximación de las teorías del riesgo en un estudio de caso en el Sur de Brasil. Ambiente \& Sociedade, v.17, n.1, p.133150, 2014

FIGUEIREDO, J. A. S.; CAVASINI, R.; MARTINS, D. P.; GRABOWSKI, G.. Turismo, educação e recuperação ambiental? Uma proposta para transformação e valorização de áreas de risco no sul do Brasil. In: INTERNATIONAL TOURISM CONGRESS (ITC'17), 9. Anais. Peniche, 2017.

GIL, A. C.. Métodos e técnicas de pesquisa social. São Paulo: Atlas, 2008

GIDDENS, A.. Consecuencias de la modernidad. Madrid: Alianza Universidad, 1993.

GUIVANT, J.. A trajetória das análises de risco: da periferia ao centro da teoria social. Revista Brasileira de Informações Bibliográficas, n.46, 1998.

IBGE. Instituto Brasileiro de Geografia e Estatística. Censo demográfico 2010: características da população e dos domicílios. Rio de Janeiro: IBGE, 2011.

JOFFE, H.. Risk and "the other". Cambrige University Press, 1999.

KATES, R. W.. Hazard and choice perception in flood plain management. Chicago: University of Chicago, 1962.

LATUS. Consultoria, Pesquisa e Assessoria de Projetos: Prefeitura municipal de Novo Hamburgo. Estratégias de Ação: Plano Local de Habitação de Interesse Social - PLHIS. Novo Hamburgo: 2010.

LEEDS, A.. Poder local em relação com instituições de poder supralocal. In: LIMA, N. T.; LEEDS, A.; LEEDS, E.. A sociologia do Brasil Urbano. 2 ed. Rio de Janeiro: FIOCRUZ, 2015. DOI: http://doi.org/10.7476/9788575415740
LONDE, L. R.; COUTINHO, M. P.; GREGÓRIO, L. T.; SANTOS, L. B.. SORIANO, E. Desastres relacionados à Água no Brasil: Perspectivas e Recomendações. Ambiente \& Sociedade. São Paulo, v.17, n.4, p.133-152, 2014.

LOPES, A. R. S.. Castigo do céu ou provação divina: consciência histórica dos desastres no sul de Santa Catarina (1974-2004). Revista Territórios \& Fronteiras, Cuiabá, v.11, n.1, 2018.

MENDES, J.. Sociologia do Risco: uma breve introdução e algumas lições. Imprensa da Universidade de Coimbra, 2015.

MYERS, M. D.; NEWMAN, M.. The Qualitative Interview in IS Research: Examining The Craft. Information and Organization, v.17, n.1, p.2-26, 2007.

MYHRE, G.; ALTERSKJER, K.; STJERN, C. W.. Frequency of extreme precipitation increases extensively with event rareness under global warming. Scientific Reports, v.9, n.16063, 2019. DOI: https://doi.org/10.1038/s41598-01952277-4

NATENZON, C. E.. Reflexiones sobre riesgo, vulnerabilidad social y prevención de catástrofes. Ciência \& Trópico, v.40, n.1, 2016

NOVO HAMBURGO. Prefeitura Municipal de Novo Hamburgo/RS. Lei n. 1216, de 20 de dezembro de 2004. Institui o Plano Diretor Urbanístico Ambiental - PDUA do município de Novo Hamburgo e dá outras providências. Novo Hamburgo, 2004.

O'CONNOR, R. E.; BORD, R. J. Y.; FISHER, A.. Risk perceptions, general environmental beliefs, and willignes to address climate change. Risk Analysis, v.19, n.3, p.461-471, 1999.

OCHA. Natural Disasters in Latin America and the Caribbean 2000-2019. Balboa: OCHA, 2020.

PÁDUA, J. A.. As bases teóricas da história ambiental. Estudos Avançados, São Paulo, v.24, n.68, 2010.

PUY, A.; ARAGONÉS, J. I.. Percepción social de los riesgos y gestión de las emergencias ambientales. Revista Desastres y Sociedad, n.8, p.39-58, 1997.

REGERT, R. M.. Análise da situação habitacional da população de baixa renda e o problema da exclusão social no Município de Novo Hamburgo - RS. Dissertação (Mestrado em Desenvolvimento Regional) - Universidade de Santa Cruz do Sul, Santa Cruz do Sul, 2010.

ROLNIK, R.. A construção de uma política fundiária e de planejamento urbano para o país: avanços e desafios. 12 ed. IPEA, 2006

ROLNIK, R.. Estatuto da Cidade: instrumento para as cidades que sonham crescer com justiça e beleza. Estatuto da Cidade: novas perspectivas para reformas urbanas. Caderno Polis, n.4, p.64, 2001.

SELBACH, J. F.. Novo Hamburgo 1927 - 1997: os espaços de sociabilidade na gangorra da modernidade. Dissertação (Mestrado em Planejamento Urbano e Regional) - 
Universidade Federal do Rio Grande do Sul, Porto Alegre, 1999.

SLOVIC, P.. The Psychology of risk. Saúde e sociedade, São Paulo, v.19, n.4, p.731-747, 2010. DOI:

https://doi.org/10.1590/S0104-12902010000400002

\section{SOUZA, L. B.; ZANELA, M. E.. Percepção de riscos} ambientais: teoria e aplicações. Fortaleza: UFC, 2009.

SPOSITO, M. E. B.. Oportunidades e Desafios da Pesquisa Urbana Comparada. In: FIRKOWSKI, O. C. F.. Estudos urbanos comparados: oportunidades e desafios da pesquisa na América Latina. San Miguel de Tucumán: Universidad Nacional de Tucumán, 2016. p.123-150.

TAVARES, A. O.; MENDES, J. M.; BASTO, E.. Percepção dos riscos naturais e tecnológicos, confiança institucional e preparação para situações de emergência: $O$ caso de Portugal continental. Revista Crítica de Ciências Sociais, v.93, 2011. DOI: https://doi.org/10.4000/rccs.1380

TUAN, Y. F.. Topofilia: um estudo da percepção, atitudes e valores do meio ambiente. São Paulo: Difel, 1980.
UNISDR. Marco de Sendai para a Redução do Risco de Desastres 2015 - 2030. In: CONFERÊNCIA DAS NAÇÕES UNIDAS PARA A REDUÇÃO DO RISCO DE DESASTRE, 3. Anais. Tóquio, 2015.

VALENCIO, N.; MARCHEZINI, V.; SIENA, M.; CRISTOFANI, G.. Chuvas no Brasil: representações e práticas sociais. Revista Política e Sociedade, n.7, 2005.

VALENCIO, N.; SIENA, M.; MARCHEZINI, V.; GONÇALVES, J. C.. Sociologia dos Desastres: construção, interfaces e perspectivas no Brasil. São Carlos: RiMa, 2009.

WMO. World Meteorological Organization. United in Science 2020: A multi-organization high-level compilation of the latest climate science information. WMO, 2020.

YOUSUF, M. I.. Using experts' opinions through Delphi technique. Practical Assessment, Research \& Evaluation, v.12, n.4, p.1-9, 2007. DOI: https://doi.org/10.7275/rrph$\underline{\mathrm{t} 210}$

A CBPC - Companhia Brasileira de Produção Científica (CNPJ: 11.221.422/0001-03) detém os direitos materiais desta publicação. Os direitos referem-se à publicação do trabalho em qualquer parte do mundo, incluindo os direitos às renovações, expansões e disseminações da contribuição, bem como outros direitos subsidiários. Todos os trabalhos publicados eletronicamente poderão posteriormente ser publicados em coletâneas impressas sob coordenação da Sustenere Publishing, da Companhia Brasileira de Produção Científica e seus parceiros autorizados. Os (as) autores (as) preservam os direitos autorais, mas não têm permissão para a publicação da contribuição em outro meio, impresso ou digital, em português ou em tradução. 